\title{
Heterogeneous Monetary Policy Transmission in the Housing Market
}

\author{
MARIA CHRISTIDOU
}

University of Macedonia *

\author{
PANAGIOTIS TH. KONSTANTINOU \\ Athens University of Economics and Business and Hellenic Open University
}

\section{COSTAS ROUMANIAS}

Athens University of Economics and Business

\begin{abstract}
We document that the transmission of monetary policy to real house prices and housing investment is heterogeneous across the US states during the period $1983-2008$ and relate this heterogeneity to various state-level observable factors. We find that an expansionary monetary policy raises real house prices and residential investment at the national level, the increase being much larger for some states but smaller for others. For states with higher percentage of older people, population density, income inequality the responses are above those of the national aggregates; for states with higher poverty rates and more educated people the responses are below those of the national aggregates. Higher property tax rates are also associated with lower responses of housing investment and house prices.
\end{abstract}

Keywords: House prices, Housing Investment, Monetary policy transmission, Heterogeneity

JEL Classification: C32; E52; R31

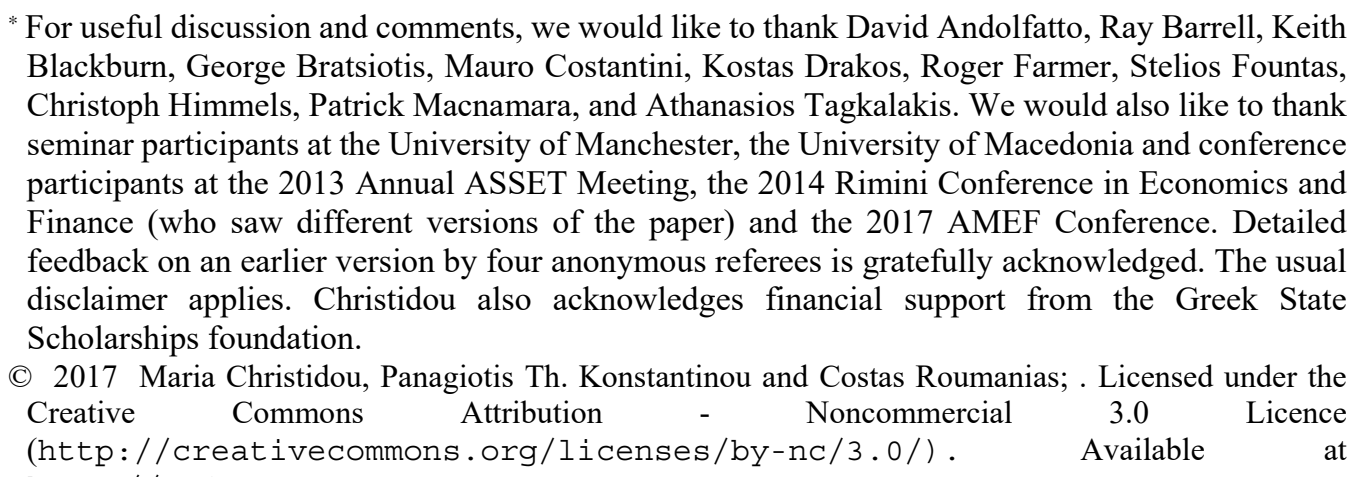
http: //rofea.org. 


\section{Introduction}

The housing market's role during the 2000s for generating strong wealth effects and its crucial role in the recent financial crises, have attracted quite some attention, leading to a set of stylised facts (see e.g. Catte et al., 2004). The most prominent of these stylized facts is that house price fluctuations have become larger over the business cycle, attracting the interest of policy makers (Girouard et al., 2006). In addition, Mishkin (2007) argues that the transmission of monetary policy may be influenced by the housing market, especially through its effect on the cost of capital, housing supply and demand, and households' wealth. In this paper we aim at assessing whether the transmission of a common monetary policy shock differes across the US states, and howe these differences relate to various observable factors.

While conventional wisdom suggests that expansionary monetary policies lead to higher (real) house prices and higher residential investment, thereby influencing the transmission mechanism throughout the economy, the exact quantitative effects on the housing market are still under investigation. ${ }^{1}$ House prices are found to be sensitive to monetary policy shocks, and in particular real house prices tend to fall after a contractionary monetary policy shock while similar findings are obtained for residential investment (e.g. Bjornland and Jacobsen (2013); Calza et al. (2013), Iacoviello and Neri (2010); Jarocinski and Smets (2008); Musso et al. (2011); Vargas-Silva (2008)). ${ }^{2}$ On the other hand, Del Negro and Otrok (2007) find that a local component has driven historical fluctuations in house prices; the effect of monetary policy shocks on the housing boom is found to be significant, but small.

Some studies have focused on the heterogeneous effects of monetary policy on housing market outcomes. For instance, Fratantoni and Schuh (2003) introduce a heterogeneous-agent VAR model for 27 US metropolitan areas and find that there is a negative response of housing investment and housing price inflation to an interest rate increase, though heterogeneous across regions both in magnitude and duration. Vargas-Silva (2008) estimates regional VAR models for the four census regions, finding a contractionary effect of monetary policy on residential investment, especially in the Midwest region. Similar results have been obtained by Gupta and Kabundi (2009) for the nine census divisions and by Gupta et al. (2010) for the four census regions; with the response being heterogeneous across regions.

Taking the aforementioned conventional wisdom as a starting point, a natural question that arises is: does a common (nation-wide) monetary policy shock generate effects on real house

\footnotetext{
${ }^{1}$ Early contributions by Goodhart and Hofmann $(2004,2007,2008)$ show the importance of house prices for the transmission of monetary policy shocks.

2 Carstensen et al. (2009) show that the response of key macroeconomic variables to a monetary policy shock is amplified in countries where house prices react more to a monetary policy shock. Iacoviello $(2000,2004)$ reports that the variability of real house prices is mostly explained by monetary factors. Finally, Sá et al. (2014) show the effect of monetary policy to be larger in countries with more developed mortgage markets
} 
prices and residential investment which are across states? And if dissimilarity of responses arises, which are the state-level factors that possibly explain the differential responses? In this paper, we focus on these questions by first characterising empirically the joint dynamics of housing prices, housing investment and interest rates. Drawing on prior work by Vargas-Silva (2008), we adopt a simple methodology that allows us to assess the effects of monetary policy in the US housing market. A novelty of our approach is that we employ separate VAR models for all 50 US states, which allow us to measure these effects in a quantitative manner and assess the degree of heterogeneity across states.

We find that an expansionary monetary policy shock leads, at a national level, to a boom in residential investment, which is accompanied by an increase in real house prices. At the state level, however, the response of both housing investment and house prices is heterogeneous, since these effects are neither uniform across states, nor always significantly different from the national aggregate. For instance, we document that for some US states, the effects of monetary policy tend to be long-lasting, whereas in other states the effects are extremely short-lived. Moreover, in some states the increase of housing investment or house prices is larger than the US-wide increase, while in others it is smaller.

A second set of results we obtain, relates to the determinants of such heterogeneity across the US states. In particular we use state-level demographic, socioeconomic and economic variables, and assess their importance in explaining the state-level heterogeneity of the responses of housing investment and prices to an expansionary monetary policy innovation. These factors account for a large fraction of the variability of price responses (between 39\% and $54 \%$ ) and a mild fraction of the variability of investment responses (between $14 \%$ and $35 \%)$. We find that states with higher fraction of population above 35 years, with higher population density and higher income inequality tend to display responses above the national aggregate. Instead, states with higher poverty rates and higher percentage of educated individuals tend to have responses below the national aggregate. Our results also indicate the important role of fiscal variables (e.g. real-estate tax rate), which can be chosen by the local governments. We find that states with higher real-estate tax rates have house prices and investment respond less relative to the national aggregate. This last finding has important implications for the effects of monetary policy in monetary unions: to the extent that local fiscal authorities co-ordinate in charging similar property tax rates, the local effects of monetary policy are going to be similar to the effects on the union-wide (or nation-wide) aggregate.

The remainder of the paper is structured as follows. In the next section, we briefly discuss the data we employ and the structure of our empirical methodology. Our basic findings are discussed in the third section, while the fourth section analyses the variation across the statelevel responses, using state-level covariates. The last section concludes. 
Review of Economic Analysis 10 (2018) 75-96

\section{Data and Empirical Methodology}

In this section, we discuss the data we employ in our analysis and give a brief overview of our empirical strategy for fleshing-out the effects of monetary policy on the housing market.

\subsection{Data}

In our work, we employ quarterly data covering the period from the first quarter of 1983 to the third quarter of $2008 .^{3}$ In tracing the effects of monetary policy on the housing market, we employ two types of data, namely macroeconomic variables that are common across US states and variables that are state-specific. The former includes real GDP, the GDP deflator, housing investment, house prices and the federal funds rate. The latter include housing investment, real house prices and a 30-years fixed mortgage rate for the 50 US states, excluding only the District of Columbia.

Measures of GDP and the GDP deflator are taken from the Bureau of Economic Analysis. ${ }^{4}$ We measure housing investment by the number of new housing units authorized by building permits, obtained from the US Census Bureau. House prices are measured by the alltransactions house price index taken from the Federal Housing Finance Agency. The federal funds rate is taken from the Federal Reserve Bank of St. Louis, while the 30-years fixed mortgage rate is obtained from Freddie Mac at the regional level and used at the state level. ${ }^{5}$ GDP and house prices are deflated using the GDP deflator. All data except the interest rates are in logarithms and seasonally adjusted. ${ }^{6}$

\subsection{Econometric Specifications}

We employ a set of Vector Autoregressive (VAR) models which have proved successful in analysing the effects of monetary policy. Our models take the form:

\footnotetext{
${ }^{3}$ The choice of the sample period reflects two concerns. First, there is evidence that before 1983, monetary policy was somewhat different and that a structural break occurs in monetary VARs around that time period (see Boivin and Giannoni, 2006, 2010; Clarida et al., 2000). Second, following the collapse of Lehman Brothers in September 2008, the FED started following 'unconventional' policies e.g. Quantitative Easing. As such policies are hard to be captured by 'shocks' to a monetary policy interest rates, especially because of the zero-lower bound constraint, we have chosen not to include data after the third quarter of 2008 in our analysis.

${ }^{4}$ In particular real GDP measures were obtained by interpolating annual (real) GDP figures using real personal income at a quarterly frequency. Similarly, GDP deflators were obtained by interpolating annual GDP deflators using state-specific (or region specific) CPI deflators.

${ }^{5}$ Freddie Mac reports long-term mortgage rate for five regions: North Central, North East, South East, South West and West. The states that belong to each region are described in the notes of Table A.1 in the appendix

${ }^{6}$ Summary statistics are provided in Table A.1 in the appendix.
} 
CHRISTIDOU, KONSTANTINOU, ROUMANIAS Monetary Policy and Housing Market

$$
\boldsymbol{B}_{i 0} \boldsymbol{y}_{i t}=\boldsymbol{\kappa}_{i}+\boldsymbol{B}_{i}(L) \boldsymbol{y}_{i t-1}+\boldsymbol{\eta}_{i t}
$$

where $\boldsymbol{y}_{i t}$ is a $p \times 1$ vector of endogenous variables observed over time $t=1,2, \ldots, T, \boldsymbol{\kappa}_{i}$ is a $p \times 1$ vector of constants, $\boldsymbol{B}_{i}(L)$ is a $p \times p$ matrix polynomial in the lag operator, $\boldsymbol{\eta}_{i t}$ is a $p \times 1$ vector of structural disturbances and $\boldsymbol{B}_{i 0}$ is a $p \times p$ matrix that describes the contemporaneous relations among the endogenous variables. As we are interested in assessing the existence of heterogeneity across US states, we allow these coefficients to vary across states $i=1,2, \ldots, 50 .^{7}$ That is we estimate a separate VAR for each state $i$, rather than pooling the coefficients in panel VAR model.

In identifying the monetary policy shock, we follow Christiano et al. (2005) in assuming that

$$
r_{t}=f\left(\mathcal{F}_{t}\right)+\epsilon_{t}
$$

where $r_{t}$ is the federal funds rate, $f(\cdot)$ is a linear function, $\mathcal{F}_{t}$ is an information set and $\epsilon_{t}$ is the monetary policy shock. We divide $\boldsymbol{y}_{i t}$ as follows:

$$
\boldsymbol{y}_{i t}^{\prime}=\left[\boldsymbol{y}_{1 t}^{\prime}, r_{t}, \boldsymbol{y}_{2 i t}^{\prime}\right]
$$

The vector $\boldsymbol{y}_{1 t}$ is composed of the variables contained in $\mathcal{F}_{t}$ and not contemporaneously affected by a monetary policy shock (which are country-wide variables), while vector $\boldsymbol{y}_{2 i t}$ consists of all the other variables in $\mathcal{F}_{t}$ (composed of state-specific variables).

In our analysis, we specify an eight-dimensional VAR with

$$
\boldsymbol{y}_{i t}=[\underbrace{y_{t}, p_{t}, i n v_{t}, h p_{t}}_{\boldsymbol{y}_{1 t}}, r_{t}, \underbrace{i n}_{\boldsymbol{y}_{2 i t} i n v_{i t}-i n v_{t}, h p_{i t}-h p_{t}, R_{i t}}]
$$

where $y_{t}$ is US-wide $(\log )$ real GDP in period $t, p_{t}$ is $(\log )$ GDP deflator, $i n v_{t}$ is $(\log )$ nationwide housing investment, $h p_{t}$ is the $(\log )$ real house price, $r_{t}$ is the federal funds rate, $i n v_{i t}-$ $i n v_{t}$ is the (log) relative housing investment for state $i, h p_{i t}-h p_{t}$ is the (log) relative real house price and $R_{i t}$ is fixed mortgage rate for 30 years. ${ }^{8}$ We estimate unrestricted VARs in levels, since the monetary transmission mechanism is a short-run phenomenon and unrestricted VARs are preferred to first-differenced or VEC models (Bagliano and Favero, 1998; Favero,

\footnotetext{
${ }^{7}$ Pesaran and Smith (1995) show that the standard fixed-effects estimator is inconsistent in dynamic panels, if there is slope heterogeneity.

${ }^{8}$ Recall that mortgage rates vary at a regional level.
} 
Review of Economic Analysis 10 (2018) 75-96

2001). The lag-length was set to two lags in all cases. ${ }^{9}$ We impose a common number of lags in all the VARs we estimate, in order to avoid obtaining impulse responses that are heterogeneous across different states, just because there may be differences in the lag structure of our models.

\section{Heterogeneity in the Monetary Transmission}

We are interested in the response of state-level housing investment and house prices to an economy-wide monetary policy shock, which we normalize to correspond to a 100-basis points reduction in the federal funds rate. For completeness, we first discuss the aggregate responses before presenting the state-level responses in the subsequent subsection.

\subsection{Responses of Aggregate Variables}

The responses of the national-wide variables are reported in Figure $1 .{ }^{10}$ We note that after an expansionary monetary policy shock corresponding to a reduction in the federal funds rate of 100 basis points, the federal funds rate is further reduced for about a year, returning to its preshock level after 2.5 years, and increasing further. Following such a disturbance, GDP increases (with a delay) and keeps on increasing, and the GDP deflator falls (almost on impact) displaying a hump-shaped response. The fact that the GDP deflator falls after a reduction in the federal funds rate points towards the so-called 'price puzzle' - such a finding was also present in early empirical studies (see Christiano et al. (1999) for a discussion). A possible explanation of this finding relates to the cost channel of monetary policy that causes prices to fall after an expansionary monetary policy shock. When the FED reduces interest rates, part of the production costs (related to financing) are also reduced leading aggregate prices to decrease. ${ }^{11}$

We also note that the reduction in the monetary policy rate induces a reduction in the 30year fixed-rate mortgage, which also falls for a period of about 2.5 years after the shock. An

\footnotetext{
${ }^{9}$ This is in accordance with standard information criteria for most states in our sample. Using four lags in the tradition of Christiano et al. $(1999,2005)$ does not affect our conclusions in any significant manner.

${ }^{10}$ These results are obtained using only nation-wide variables, employing two lags and a constant term in the VAR specification - in line with the specifications we employ to study the statespecific effects of monetary policy. The confidence intervals we report are based on 5000 bootstrap replications, using the method of Hall (1992) as described in Benkwitz et al. (2001)

${ }^{11}$ An alternative explanation of this finding is that it is due to misidentification of the monetary policy shock: the information set available to policy makers includes variables useful in forecasting inflation (e.g. commodity prices) that are not included in our specification. However, Barth and Ramey (2002) provide evidence in favor of the cost channel of monetary policy: using industry level data for the US they show that their findings are robust even when commodity prices are included in their VARs.
} 
interesting finding is that the reduction in the federal funds rate does not full pass-through to the long-term mortgage rate, possibly reflecting 'agency' problems, related to the values of houses used as collateral for borrowing. Most importantly, housing investment does not jump on impact (it takes roughly two quarters for the response to become significant) but increases markedly after that, peaking at about $17 \%$ roughly 3 years after the shock. Note that this corresponds to a change in the existing housing stock - given the definition of housing investment - rather than a simple change in values. We also find that real house prices respond with a delay (of roughly a year) peaking at about $5.5 \%$ almost 4.5 years after the shock - in line with the delayed response of housing investment.

Figure 1. Impulse Responses of National Aggregates to a Monetary Policy Shock
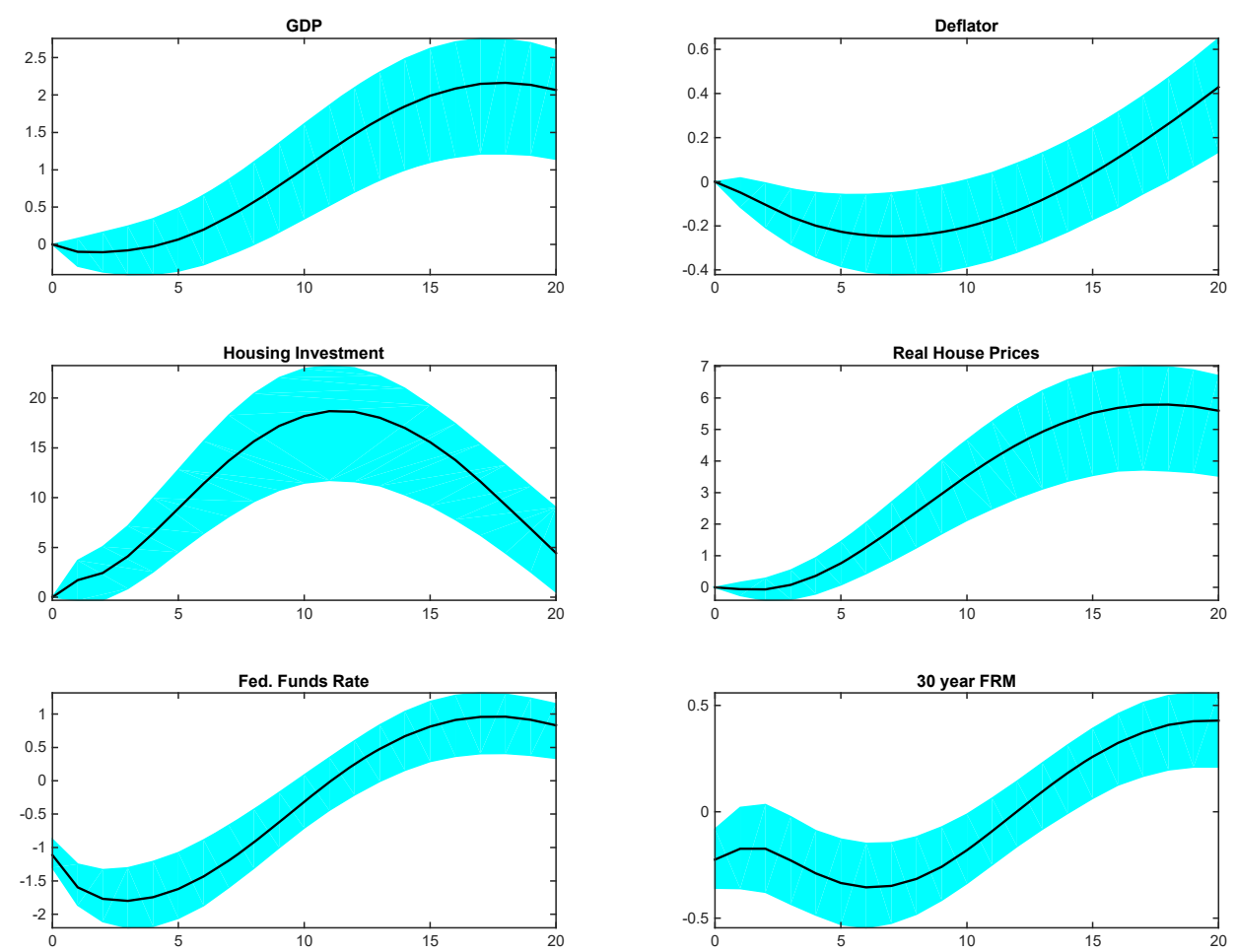

The figure plots the impulse responses of GDP, the GDP deflator, housing investment, real house prices and the 30-year fixed mortgage to an expansionary monetary policy shock (100 basis points). The shaded areas are $90 \%$ confidence intervals based on 5000 bootstrap replications using the method of Hall (1992) as described in Benkwitz et al. (2001). 


\subsection{State-Level Responses}

The results of the impulse response analysis at the state-level are shown in Figures 2 to $3 .^{12}$ Figure 2 shows the impulse responses of (relative) housing investment and Figure 3 the responses of (relative) house prices. First, we observe that the effects of monetary policy on housing investment tend to differ a lot across states. In particular, an expansionary monetary policy disturbance leads to an increase in (relative) housing investment for some states (for instance California, Delaware, Florida, Maine, New Hampshire, Montana, Utah), to a decrease for others (e.g. Mississippi, North Carolina, Ohio, Oklahoma, Oregon), while for a group of states is quite hard to distinguish (as even the sign of the impulse response changes). The key finding is that the estimated (differential) effects of monetary policy on housing investment are heterogeneous both in terms of magnitude and in terms of duration of the effect.

Second, the effects of expansionary monetary policy on real housing prices are also heterogeneous across states. We observe that there are cases in which there are large differences in the absolute magnitude (for instance in California, Delaware, Florida, Hawaii, New Jersey, Oklahoma, etc.). In many cases, the sign of the effect is different across states (in some states the responses are positive i.e. prices rise more than the national aggregate; while in others they are negative, i.e. prices rise less than the national aggregate), while the duration of the effect is also found to be heterogeneous.

To appreciate these findings better, in Figure 4 we report the cross-sectional distribution of the (point estimates of) impulse responses of relative investment and house prices at horizons of one, two, three and five years after the shock. In Figures 2 and 3 we saw that the shape of the responses was different for some states. What is clear from Figure 4 is that the distributions of impulse responses are clearly asymmetric. Moreover, the pattern of asymmetry is different at different horizons (after the shock). To understand these effects better, in the following section we explore factors that might help us in explaining these differences across states.

Our findings thus far also highlight that the transmission of monetary policy across housing markets of the same monetary union need not be homogeneous: the same shock may end up increasing prices and investment more in one part of the union and less in some other. In this perspective, a one-size-fits-all monetary policy might be problematic. We return to this issue below.

\footnotetext{
12 These effects should be interpreted as the effects of monetary policy shocks relative to the effects of such shocks to the nation-wide variables (housing investment and housing prices).
} 
CHRISTIDOU, KONSTANTINOU, ROUMANIAS Monetary Policy and Housing Market

Figure 2. Impulse Responses of (Relative) Investment Across States
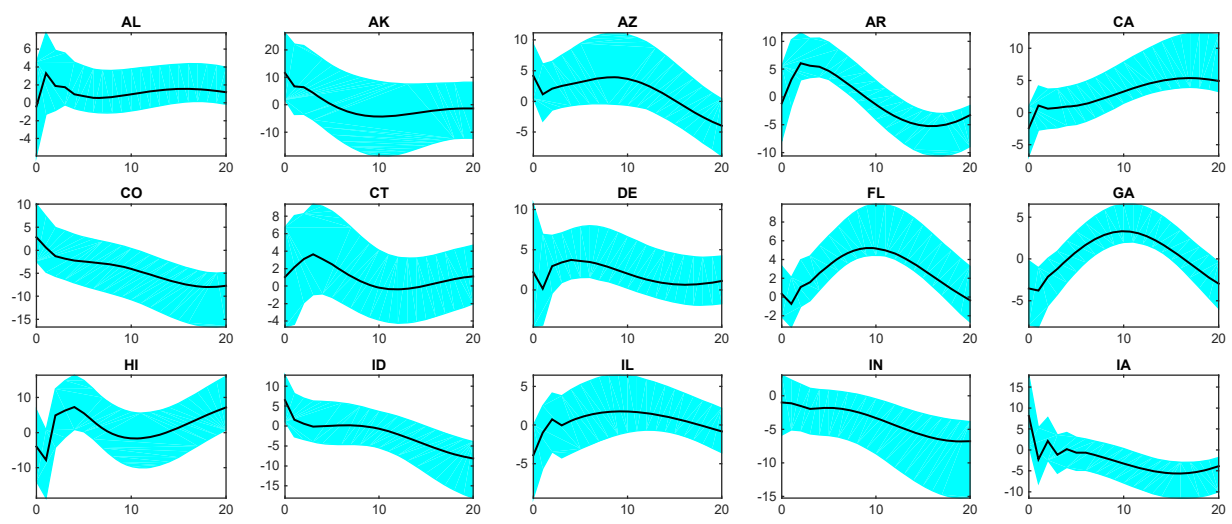

KY

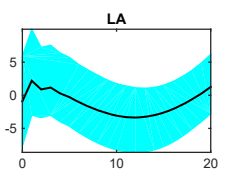

ME
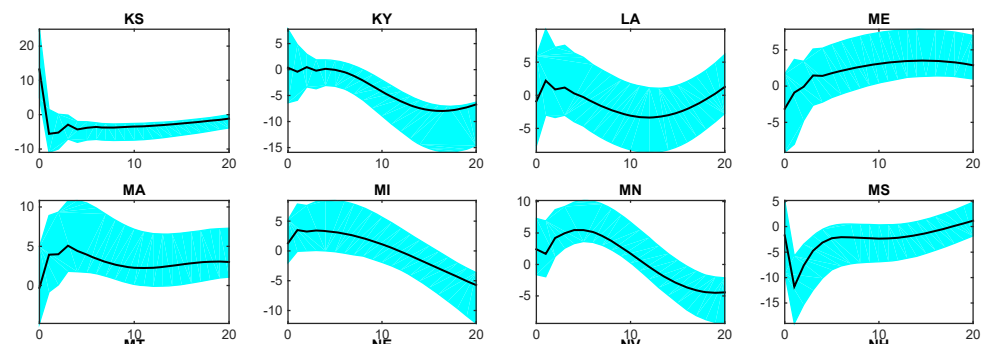

MS
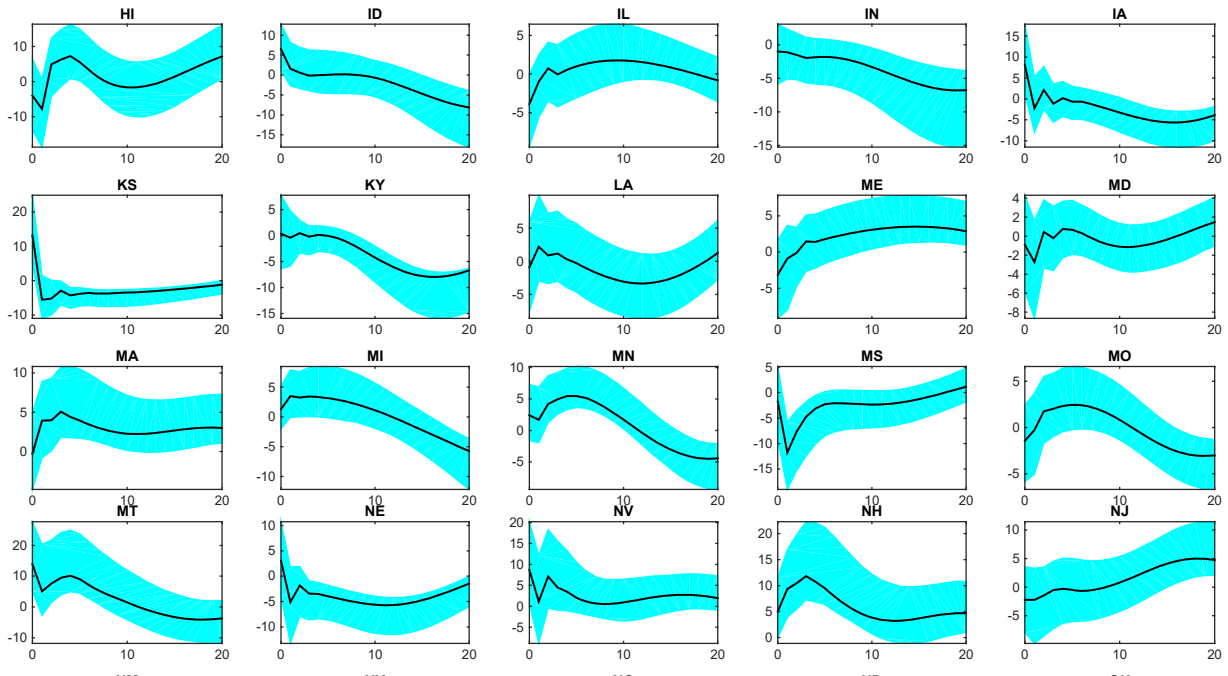

MD

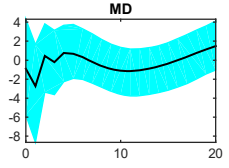

мо
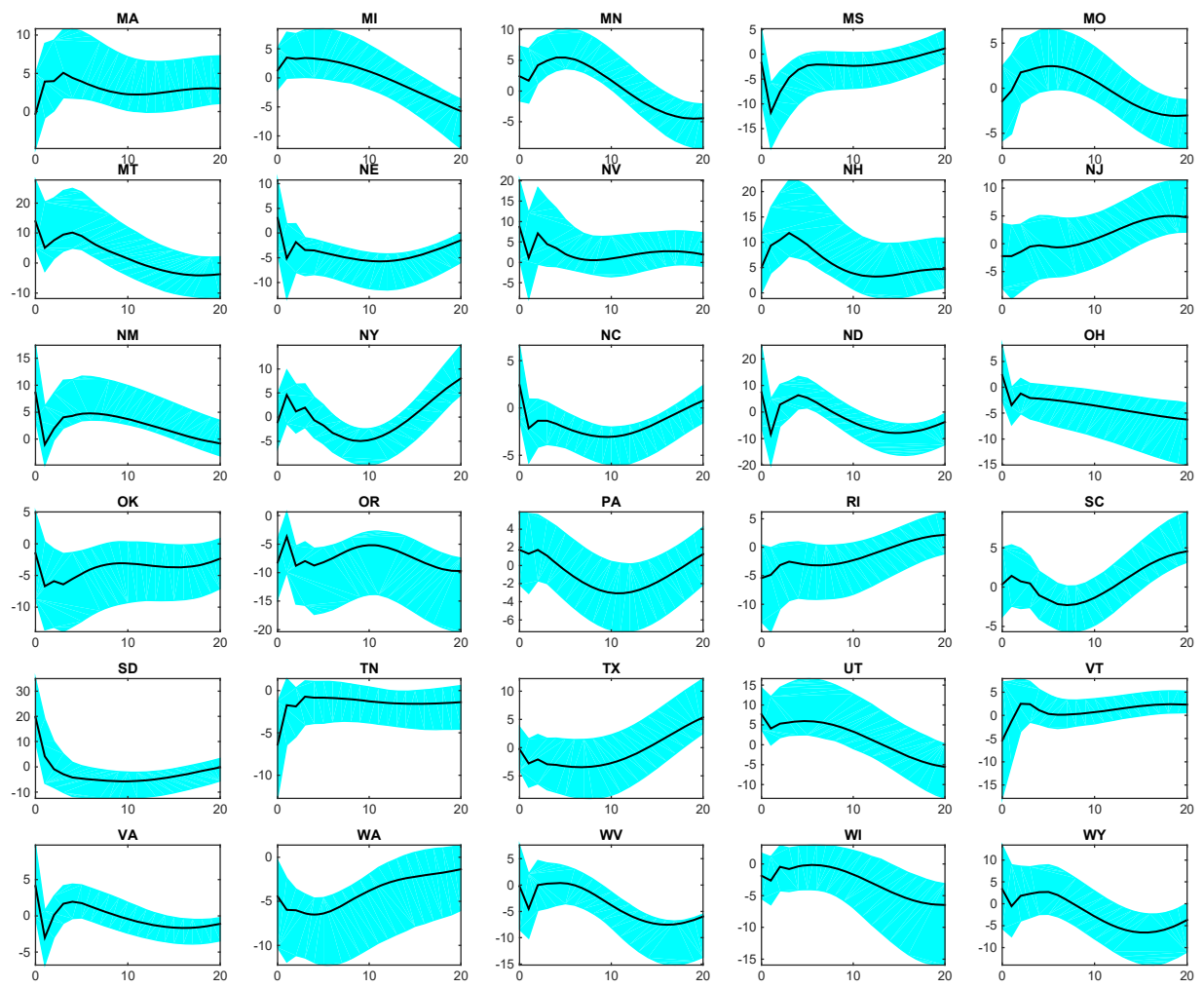

The figure plots the impulse responses of investment in state $i$ relative to the national aggregate. The shaded areas are $90 \%$ confidence intervals based on 5000 bootstrap replications using the method of Hall (1992) as described in Benkwitz et al. (2001). 
Review of Economic Analysis 10 (2018) 75-96

Figure 3. Impulse Responses of (Relative) House Prices Across States


The figure plots the impulse responses of real house prices in state $i$ relative to the national aggregate. See also notes for Figure 2. 
Figure 4. Heterogeneity of IRFs of Housing Prices and Investment
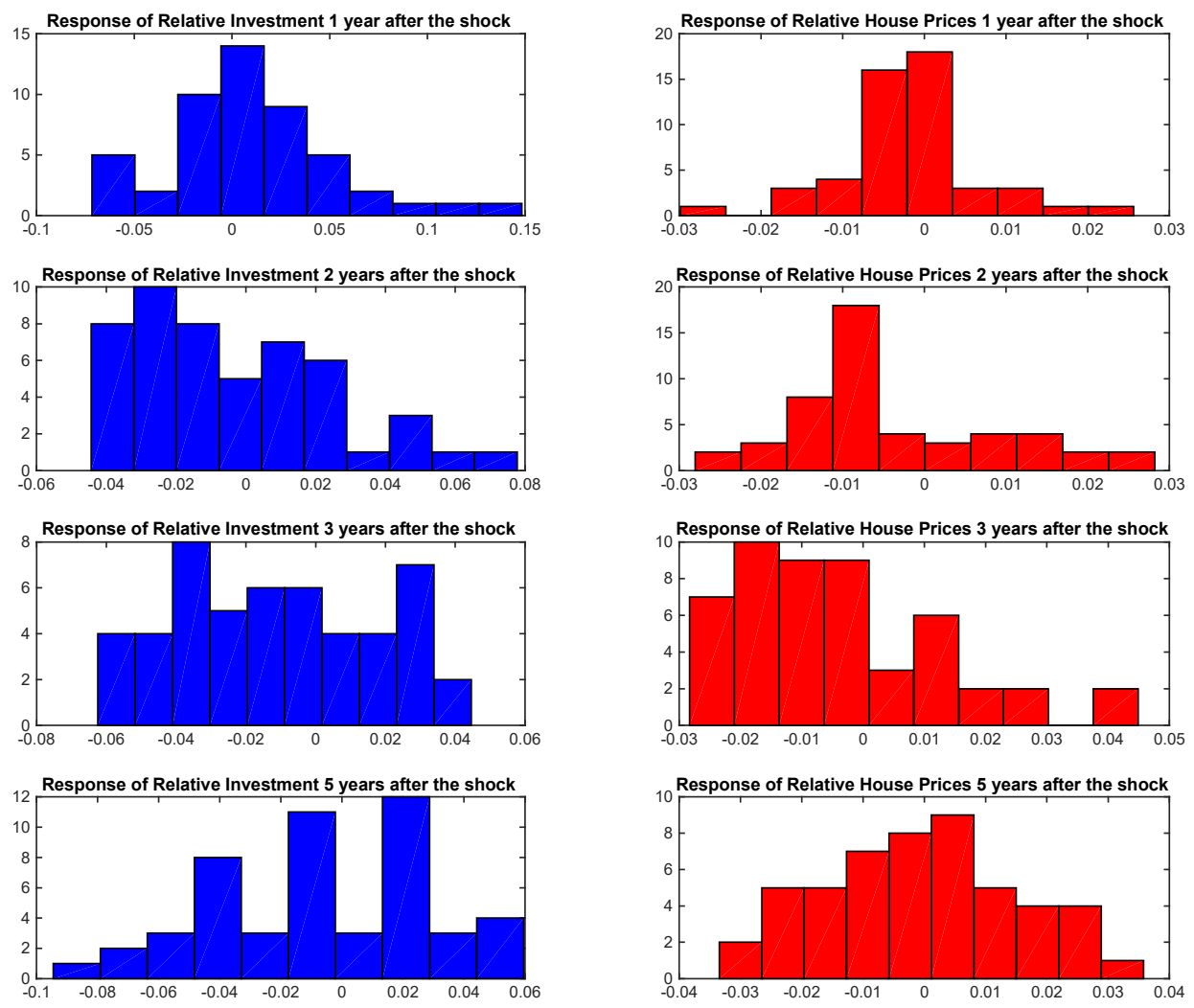

The figure plots the cross-sectional distribution of the (point estimates of) impulse responses of housing investment and real house prices in state $i$ relative to the national aggregates, one, two three and five years after the monetary policy shock.

\section{Explaining the Heterogeneity in State-Level Responses}

\subsection{Empirical Specification}

To understand the differential responses of state-level housing investment and housing prices to a monetary policy shock, it is useful to think of factors that potentially influence the effects of monetary policy at the state level. In order to evaluate the source of these differences, we use the estimated impulse responses as a dependent variable in a set of cross-state regressions. As the effects of the monetary policy shocks seem very persistent (see Figures $2 \& 3$ ), we focus on the impulse responses at horizons of 1-year, 2-years, 3-years and 5-years after the shock and regress these on key characteristics that might influence cross-sectional heterogeneity. The regressions we estimate are of the form: 
Review of Economic Analysis 10 (2018) 75-96

$$
I R_{i}^{h}=c+\boldsymbol{\beta}^{\prime} \boldsymbol{X}_{i}+u_{i}
$$

where $I R_{i}^{h}$ is the estimated the impulse response of state $i$ to a monetary policy shock $h$ periods after the shock, and $\boldsymbol{X}_{i}$ is a vector of state-specific explanatory covariates.

The state-level covariates we consider can be divided into three major categories: demographic factors, socio-economic factors and economic variables. ${ }^{13}$ The demographic factors we consider are the share of adults aged 35-and above and overall population density. Presumably, the housing market in states with a higher percentage of population aged-35-orolder will be more influenced by monetary policy, as people in these age groups are more active in the housing market (buying and/or selling). ${ }^{14}$ So in states with higher percentage of younger individuals (less than 35 years old) we expect the responses of both investment and prices to be more muted (e.g. lower than the national aggregate). Similarly, population density might also influence how housing investment and housing prices respond to favourable monetary conditions. Prices in more densely populated states are expected to respond more relative to the national aggregate, because of the limited supply of land. Along the same lines, as time passes by, the demand for new or better quality houses might also lead the response of investment to be higher in more densely populated states.

The socio-economic factors we consider are income inequality, poverty rate and education. ${ }^{15}$ It is quite clear that poor people generally cannot afford to buy homes, so we expect that a higher incidence of poverty rates will lead to responses of both house prices and housing investment to be more contained and fall short relative to the national aggregate. Likewise, the level of education might affect how people perceive monetary policy and its effects on housing market outcomes. More educated people are thus expected to respond less aggressively to laxer economic conditions. If this is the case, we expect the higher the fraction of educated people in a particular state, the lower the response of both housing investment and prices (again relative to the national aggregate). We also feel that measures of income inequality are important to the extent that they proxy for groups of borrowing-constrained individuals: the higher inequality is, the larger the fraction of individuals that face constraints on borrowing

\footnotetext{
13 These are averages over the period we consider in our sample.

${ }^{14}$ The percentage of people with age 35 and above, as well as population density has been obtained from the US Census Bureau.

${ }^{15}$ Income inequality data comes from Frank (2009). The poverty rate and the percentage of persons who have completed secondary education were collected from the US Census Bureau. Bampinas et al. (2017) show that income inequality and demographic factors affect the housing wealth effect across 48 US states.
} 
against permanent income. ${ }^{16}$ As these constraints are relaxed, individuals that were constrained will be more actively involved in the housing market, driving prices and housing investment up.

Finally, the economic variables that we consider are the average property tax rate and the percent of homeownership rate. ${ }^{17}$ The higher the property tax rates in a state, the lower the net financial gain from higher house prices and/or from investment in new houses. As such, we expect that in states with high property taxes individuals will have less of a motive to invest and/or buy new homes; thereby high tax rates should be associated with lower responses of both house prices and investment. The effects of the homeownership rate on the other hand are unclear. To the extent that houses are viewed as assets, we expect that the higher the degree homeownership the more responsive prices and investment will be - as individuals trade more actively in the housing market, also seeking new investment opportunities. If, on the other hand, houses are mostly seen as a source of a service flow, then a higher degree homeownership could well lead to lower responses of both prices and investment.

\subsection{Empirical Findings}

The results from various sets of cross-sectional regressions are reported in Table 1 (for investment responses) and Table 2 (for price responses). Looking first at investment one year after the shock, we note that states with higher poverty rates, higher percentage of educated individuals, and higher property taxes tend to witness responses of housing investment that falls short of the response of the national aggregate. Similar findings arise at the two-year horizon, the only difference being that higher home ownership rates lead to investment responses that are above the national aggregate. The other variables (e.g. age structure, population density and income inequality) do not seem to matter for the responses of investment at short time horizons.

Looking at medium horizons ( 3 and 5 years after the shock) we find that poverty rates, the percentage of educated individuals and property taxes do not explain the differential response of investment to a monetary policy shock, unlike what happens at short horizons. In addition, we find that population density leads to an increase the difference in the impulse responses relative to the national aggregate both at the 3-year and 5-year horizon - in contrast to what happens at short horizons. Finally, we note that at a five-year horizon the homeownership rate significantly reduces the differential response of investment - contrary to our finding at the two-year horizon. One interpretation of this finding is that at shorter horizons, houses are moreviewed as "assets" and individuals invest more actively in new houses. As time passes by

\footnotetext{
${ }^{16}$ Mian and Sufi (2011) find that younger and low credit scores households, have stronger home equity-based borrowing.

${ }^{17}$ The former has been calculated using data from the tax foundation, while the later comes from the US Census Bureau.
} 
Review of Economic Analysis 10 (2018) 75-96

TABLE 1. Housing Investment Heterogeneity

Panel A: Housing Investment Heterogeneity at Short Horizons

\begin{tabular}{|l|c|c|c|c|c|c|c|r|}
\hline & $(1)$ & $(2)$ & $(3)$ & $(4)$ & $(5)$ & $(6)$ & $(7)$ & $(8)$ \\
\hline VARIABLES & \multicolumn{3}{|c|}{1 year after the shock } & \multicolumn{3}{|c|}{ 2 years after the shock } \\
\hline \hline Age 35+ & -0.0842 & & & 0.0625 & -0.0904 & & & -0.0934 \\
& $(0.270)$ & & & $(0.2709)$ & $(0.261)$ & & & $(0.1992)$ \\
\hline Population & 0.0008 & & & 0.0019 & 0.0065 & & & 0.0230 \\
Density & $(0.019)$ & & & $(0.0236)$ & $(0.014)$ & & & $(0.0152)$ \\
\hline Inequality & & 0.1747 & & 0.4051 & & -0.0033 & & 0.3045 \\
Gini & & $(0.2375)$ & & $(0.3126)$ & & $(0.2192)$ & & $(0.2452)$ \\
\hline Poverty rate & & $-0.2916^{*}$ & & $-0.5423^{* * *}$ & & -0.1111 & & $-0.3195^{*}$ \\
& & $(0.1648)$ & & $(0.1820)$ & & $(0.1332)$ & & $(0.1641)$ \\
\hline Education (\% & & -0.1460 & & $-0.1776^{*}$ & & -0.1095 & & $-0.1654^{*}$ \\
High school) & & $(0.1022)$ & & $(0.0944)$ & & $(0.0842)$ & & $(0.0856)$ \\
\hline Home & & & 0.0217 & 0.1494 & & & 0.1205 & $0.2655^{* * *}$ \\
Ownership Rate & & & $(0.103)$ & $(0.1545)$ & & & $(0.0782)$ & $(0.0884)$ \\
\hline Real-Estate & & & -1.0593 & $-2.6733^{* *}$ & & & -1.1855 & $-2.1249^{* *}$ \\
Tax Rate & & & $(1.265)$ & $(1.2440)$ & & & $(0.9190)$ & $(0.9219)$ \\
\hline Constant & 0.0656 & 0.0603 & 0.0038 & -0.1377 & 0.0566 & 0.1006 & -0.0752 & -0.1118 \\
& $(0.181)$ & $(0.1541)$ & $(0.076)$ & $(0.2983)$ & $(0.177)$ & $(0.1294)$ & $(0.0551)$ & $(0.2223)$ \\
\hline Observations & 50 & 50 & 50 & 50 & 50 & 50 & 50 & 50 \\
\hline R-squared & 0.0021 & 0.0636 & 0.0156 & 0.1489 & 0.0059 & 0.0310 & 0.0684 & 0.2020 \\
\hline
\end{tabular}

(periods after the shock) and houses are viewed more as "capital" that provides a service flow, high investment in new houses becomes less attractive.

Turning next to house price responses we note that states with higher population density and higher income inequality tend to have prices that respond more relative to the national aggregate. This is so both at short (1-2 years after the shock) but also at medium horizons (3-5 years after the shock). ${ }^{18}$ On the other hand we find that states with higher poverty rates display house price responses well below the national aggregate, especially at horizons of two years after the shock and beyond. A similar finding arises for the homeownership rate at the same horizons after the shock: the higher the homeownership rate the lower the price response.

\footnotetext{
${ }^{18}$ The only exception is the effect of income inequality at the three-year horizon which is found to be insignificant.
} 
CHRISTIDOU, KONSTANTINOU, ROUMANIAS Monetary Policy and Housing Market

Table 1, Panel B: Housing Investment Heterogeneity at Medium Horizons

\begin{tabular}{|l|c|c|c|c|c|c|c|c|c|}
\hline & $(1)$ & $(2)$ & $(3)$ & $(4)$ & $(5)$ & $(6)$ & $(7)$ & $(8)$ \\
\hline VARIABLES & \multicolumn{3}{|c|}{3 years after the shock } & \multicolumn{3}{|c|}{5 years after the shock } \\
\hline Age 35+ & -0.2534 & & & -0.2156 & -0.2348 & & & -0.0063 \\
& $(0.2163)$ & & & $(0.1970)$ & $(0.2848)$ & & & $(0.2584)$ \\
\hline Population & $0.0376^{* * *}$ & & & $0.0465^{* * *}$ & $0.0707^{* * *}$ & & & $0.0590^{* *}$ \\
Density & $(0.0124)$ & & & $(0.0156)$ & $(0.0130)$ & & & $(0.0221)$ \\
\hline Inequality & & 0.1168 & & 0.2243 & & $0.4652^{*}$ & & 0.1603 \\
(Gini) & & $(0.2218)$ & & $(0.2634)$ & & $(0.2528)$ & & $(0.2320)$ \\
\hline Poverty rate & & -0.1546 & & -0.1656 & & -0.2071 & & 0.0900 \\
& & $(0.1413)$ & & $(0.1837)$ & & $(0.1675)$ & & $(0.1903)$ \\
\hline Education (\% & & -0.0999 & & -0.1342 & & -0.1618 & & -0.1374 \\
High school) & & $(0.0979)$ & & $(0.1047)$ & & $(0.1394)$ & & $(0.1290)$ \\
\hline Home & & & -0.0583 & 0.1108 & & & $-0.4280^{* * * *}$ & $-0.2953^{*}$ \\
Ownership Rate & & & $(0.0906)$ & $(0.0916)$ & & & $(0.0960)$ & $(0.1482)$ \\
\hline Real-Estate & & & -0.6678 & -1.2504 & & & 0.3099 & 0.1794 \\
Tax Rate & & & $(1.0031)$ & $(1.0894)$ & & & $(1.2436)$ & $(1.4104)$ \\
\hline Constant & 0.1521 & 0.0178 & 0.0330 & 0.0578 & 0.1362 & -0.1278 & $0.2810^{* * *}$ & 0.1891 \\
& $(0.1460)$ & $(0.1407)$ & $(0.0640)$ & $(0.2356)$ & $(0.1943)$ & $(0.2013)$ & $(0.0658)$ & $(0.2180)$ \\
\hline Observations & 50 & 50 & 50 & 50 & 50 & 50 & 50 & 50 \\
\hline R-squared & 0.1113 & 0.0360 & 0.0171 & 0.1766 & 0.1836 & 0.0808 & 0.2389 & 0.3489 \\
\hline
\end{tabular}

Notes for Table 1. Panel A reports cross-sectional regression results for short horizon responses (1 and 2 years after the shock) and Panel B regression results for medium horizon responses ( 3 and 5 years after the shock) of housing investment. Columns (1) and (5) report results for demographic variables only; Columns (2) and (6) results for socio-economic variables only; Columns (3) and (7) results for economic variables only; and Columns (4) and (8) including all covariates. Robust standard errors in parentheses. ${ }^{* * *}$, and ${ }^{* * *}$ denote significance at the $10 \%, 5 \%$ and $1 \%$ level respectively.

We also find that at a two-year and a three-year horizon, the percentage of individuals above 35 years of age significantly increases the differences of the price responses. Finally, we note that real-estate taxes do not have any significant impact on price response differentials at relatively short horizons (1-2 years after the shock). Looking at medium horizons (3-5 years after the shock) however, our results show that in states with higher property taxation, price responses tend to fall short of the national aggregate in a statistically significant manner. 
Review of Economic Analysis 10 (2018) 75-96

TABLE 2. House Price Heterogeneity

Panel A: Housing Price Heterogeneity at Short Horizons

\begin{tabular}{|c|c|c|c|c|c|c|c|c|}
\hline & (1) & (2) & (3) & (4) & (5) & (6) & (7) & (8) \\
\hline VARIABLES & \multicolumn{4}{|c|}{1 year after the shock } & \multicolumn{4}{|c|}{2 years after the shock } \\
\hline Age 35+ & $\begin{array}{c}0.0435 \\
(0.0757)\end{array}$ & & & $\begin{array}{c}0.0737 \\
(0.0659)\end{array}$ & $\begin{array}{c}0.0686 \\
(0.0716)\end{array}$ & & & $\begin{array}{c}0.1817^{* * *} \\
(0.0535)\end{array}$ \\
\hline \begin{tabular}{|l} 
Population \\
Density
\end{tabular} & $\begin{array}{c}0.0158^{* * *} \\
(0.0038)\end{array}$ & & & $\begin{array}{l}0.0108^{*} \\
(0.0055)\end{array}$ & $\begin{array}{c}0.0306^{* * * *} \\
(0.0045)\end{array}$ & & & $\begin{array}{c}0.0203 * * * \\
(0.0069)\end{array}$ \\
\hline \begin{tabular}{|l} 
Inequality \\
(Gini)
\end{tabular} & & $\begin{array}{l}0.1173^{* *} \\
(0.0452)\end{array}$ & & $\begin{array}{l}0.1022^{*} \\
(0.0599)\end{array}$ & & $\begin{array}{l}0.1527^{*} \\
(0.0876)\end{array}$ & & $\begin{array}{l}0.1164^{*} \\
(0.0689)\end{array}$ \\
\hline Poverty rate & & $\begin{array}{c}-0.1117 * * * \\
(0.0370)\end{array}$ & & $\begin{array}{l}-0.0676 \\
(0.0424)\end{array}$ & & $\begin{array}{c}-0.1951^{* * *} \\
(0.0515)\end{array}$ & & $\begin{array}{c}-0.1520^{* *} \\
(0.0609)\end{array}$ \\
\hline $\begin{array}{l}\text { Education (\% } \\
\text { High school) }\end{array}$ & & $\begin{array}{c}0.0250 \\
(0.0244)\end{array}$ & & $\begin{array}{c}0.0211 \\
(0.0243)\end{array}$ & & $\begin{array}{c}0.0111 \\
(0.0357)\end{array}$ & & $\begin{array}{c}0.0079 \\
(0.0275)\end{array}$ \\
\hline $\begin{array}{l}\text { Home } \\
\text { Ownership Rate }\end{array}$ & & & $\begin{array}{c}-0.0535^{* *} \\
(0.0262)\end{array}$ & $\begin{array}{l}-0.0235 \\
(0.0292)\end{array}$ & & & $\begin{array}{c}-0.1219^{* * *} \\
(0.0374)\end{array}$ & $\begin{array}{l}-0.0793 * \\
(0.0432)\end{array}$ \\
\hline $\begin{array}{l}\text { Real-Estate } \\
\text { Tax Rate }\end{array}$ & & & $\begin{array}{c}0.5982 * * \\
(0.2556)\end{array}$ & $\begin{array}{c}0.1638 \\
(0.2561)\end{array}$ & & & $\begin{array}{c}0.4489 \\
(0.4173)\end{array}$ & $\begin{array}{l}-0.4929 \\
(0.3797)\end{array}$ \\
\hline Constant & $\begin{array}{l}-0.0318 \\
(0.0521)\end{array}$ & $\begin{array}{c}-0.0743^{* *} \\
(0.0366)\end{array}$ & $\begin{array}{c}0.0318 \\
(0.0190)\end{array}$ & $\begin{array}{l}-0.1056^{*} \\
(0.0567)\end{array}$ & $\begin{array}{l}-0.0553 \\
(0.0491)\end{array}$ & $\begin{array}{l}-0.0768 \\
(0.0628)\end{array}$ & $\begin{array}{c}0.0768^{* * * *} \\
(0.0270)\end{array}$ & $\begin{array}{l}-0.1267^{*} \\
(0.0642)\end{array}$ \\
\hline Observations & 50 & 50 & 50 & 50 & 50 & 50 & 50 & 50 \\
\hline R-squared & 0.2352 & 0.2164 & 0.1787 & 0.3940 & 0.3558 & 0.2118 & 0.2019 & 0.5360 \\
\hline
\end{tabular}

\subsection{Discussion and Policy Implications}

Our results above indicate that while income inequality and the percentage of people with age above 35 years tend to produce higher price responses, they exert no influence on the responses of housing investment. On the other hand, while the level of education is associated with lower investment responses, education does not seem to matter for house price responses. Moreover, we observe that higher poverty rates and higher population density lead to responses of housing investment and prices that are below the national aggregate - this effect holds especially at medium horizons as far as investment is concerned. ${ }^{19} \mathrm{We}$ also find that a higher percentage of

\footnotetext{
${ }^{19}$ To be more precise the negative effect of poverty rates on housing investment responses is found at horizons of two years after the shock and above, while the negative effect of population density is found to hold at horizons of three years after the shock and above.
} 
CHRISTIDOU, KONSTANTINOU, ROUMANIAS Monetary Policy and Housing Market

Figure 2, Panel B: House Price Heterogeneity at Medium Horizons

\begin{tabular}{|l|c|c|c|c|c|c|c|c|}
\hline & $(1)$ & $(2)$ & $(3)$ & $(4)$ & $(5)$ & $(6)$ & $(7)$ & $(8)$ \\
\hline VARIABLES & \multicolumn{3}{|c|}{ 3 years after the shock } & \multicolumn{2}{|c|}{5 years after the shock } \\
\hline \hline Age 35+ & 0.0110 & & & $0.1906^{* *}$ & -0.0982 & & & 0.0717 \\
& $(0.1003)$ & & & $(0.0787)$ & $(0.1045)$ & & & $(0.0765)$ \\
\hline Population & $0.0369^{* * *}$ & & & $0.0236^{* * *}$ & $0.0367^{* * *}$ & & & $0.0270^{* * *}$ \\
Density & $(0.0049)$ & & & $(0.0072)$ & $(0.0046)$ & & & $(0.0067)$ \\
\hline Inequality & & 0.2068 & & 0.1545 & & $0.2370^{* *}$ & & $0.1950^{*}$ \\
(Gini) & & $(0.1300)$ & & $(0.1101)$ & & $(0.1138)$ & & $(0.1152)$ \\
\hline Poverty rate & & $-0.2447^{* * *}$ & & $-0.2211^{* * *}$ & & $-0.2178^{* * *}$ & & $-0.2003^{* *}$ \\
& & $(0.0616)$ & & $(0.0815)$ & & $(0.0618)$ & & $(0.0780)$ \\
\hline Education (\% & & 0.0005 & & 0.0009 & & -0.0067 & & -0.0082 \\
High school) & & $(0.0447)$ & & $(0.0369)$ & & $(0.0489)$ & & $(0.0385)$ \\
\hline Home & & & $-0.1720^{* * *}$ & $-0.1124^{* *}$ & & & $-0.1718^{* * *}$ & $-0.0853^{*}$ \\
Ownership Rate & & & $(0.0440)$ & $(0.0485)$ & & & $(0.0385)$ & $(0.0460)$ \\
\hline Real-Estate & & & 0.0774 & $-1.1261^{* *}$ & & & -0.2579 & $-1.2570^{* *}$ \\
Tax Rate & & & $(0.5214)$ & $(0.4967)$ & & & $(0.5359)$ & $(0.5062)$ \\
\hline Constant & -0.0184 & -0.0951 & $0.1137^{* * *}$ & -0.1136 & 0.0570 & -0.1096 & $0.1177^{* * *}$ & -0.0689 \\
& $(0.0686)$ & $(0.0826)$ & $(0.0315)$ & $(0.1051)$ & $(0.0709)$ & $(0.0754)$ & $(0.0274)$ & $(0.1045)$ \\
\hline Observations & 50 & 50 & 50 & 50 & 50 & 50 & 50 & 50 \\
\hline R-squared & 0.3002 & 0.2062 & 0.2231 & 0.5332 & 0.2878 & 0.1805 & 0.2264 & 0.4948 \\
\hline
\end{tabular}

Notes for Table 2: Panel A reports cross-sectional regression results for short horizon responses (1 and 2 years after the shock) and Panel B regression results for medium horizon responses ( 3 and 5 years after the shock) of real house prices. See also notes for Table 1.

homeownership is associated with response of house prices which fall short of the national aggregate, especially at horizons beyond two years after the shock. Along similar lines, we note that a high degree of homeownership also leads to responses of housing investment below the national aggregate at medium horizons (five years after the shock); but to responses higher at shorter horizons (two years after the shock).

The influence of the variables discussed above on the heterogeneity of the responses of the housing variables is important, but these are factors that do not easily change and do not allow for policy intervention. However, if such differences are not taken into account by monetary authorities, a common shock might well lead to different wealth effects across countries. The only variable which can be used as a policy instrument and may be co-ordinated across states is the property tax rate. Our findings in Tables 1 and 2 indicate that property taxes make the 
differential response of housing investment negative at short horizons (up to two years after the shock); and the differential response of house prices also negative at longer horizons (three and five years after the shock). So, to the extent that a particular state would like to see house prices and investment rise faster than the nation-wide aggregates, it would simply have to reduce property taxation - so that it is below the nation-wide average property tax rate. This finding has an important implication for the effects of monetary policy across a monetary union: local governments that want to push for higher residential investment following and expansionary monetary policy, they also have to follow an expansionary fiscal policy by reducing property taxes, but at the 'cost' of higher real house prices. ${ }^{20}$

The second important implication that arises is that the only way to achieve a more homogeneous effect of monetary policy across states (or countries in a monetary union) would be for the states to co-ordinate in a more homogeneous taxation as well - provided that all the other factors are not so easily influenced by policy. As far as local governments charge the same property tax rate, or at least a tax rate that is close to the nation-wide (or union-wide) average, the effects of monetary policy are going to be more similar across states.

\section{Conclusions}

The goal of this paper has been to investigate the effect of monetary policy on real house prices and housing investment, as these are important determinants of the monetary transmission mechanism. To this end, we estimated VAR models for all 50 US states, in order to assess the differential effect of a common monetary policy on real house prices and investment. Our first set of findings (at the national level) indicates that our results are consistent with the cost channel of monetary policy, under which an expansionary monetary policy shock leads to a (temporary) fall in aggregate prices. However national residential investment and national (real) house prices are found to increase. Our second set of empirical findings suggests that transmission of monetary policy is heterogeneous across US states: in most cases, the responses of residential investment and real house prices to a common stimulus differ markedly across different states relative to the national aggregate.

In order to identify sources of this heterogeneity in responses, we have resorted to a set of cross-sectional regressions. In these models, the dependent variables were the impulse responses across the US states and the explanatory variables were a set of demographic, socioeconomic and economic variables. We find that these variables explain between $18 \%$ and $35 \%$ of the variation of investment responses and between $39 \%$ and $54 \%$ of the variation of price responses. One important conclusion that comes out of these results, is that a common monetary policy that does not take into account differences of such factors across countries (most of

\footnotetext{
${ }^{20}$ It could well be the case that such a reduction is property taxes is budget neutral. But even in this case, lower property taxes are going to fuel both residential investment and real house prices.
} 
which are beyond the control of monetary authorities), will end up influencing house prices and investment in different ways across countries, introducing heterogeneity and creating different wealth effects - leading to differential welfare gains and losses.

A second set of implications relates to property taxes, which are an important driver of this heterogeneity: local governments may enhance residential investment (relative to the national aggregate) by reducing their tax rates, at the 'cost' of rising house prices. On the other hand, if local governments decide (or are forced to by some commitment mechanism) to coordinate on the property tax rates they charge, the effects of monetary policy are going to be more homogeneous. Note that this can be achieved without local governments having to charge the same tax rate. Rather, they need to charge property tax rates that are close to the nation/unionwide average.

\section{References}

Bagliano, F. C. and C. Favero (1998), Measuring Monetary Policy with VAR Models: An Evaluation, European Economic Review, 42(6), 1069-1112.

Bampinas, G., Konstantinou, P. and Panagiotidis, T. (2017) Inequality, demographics and the housing wealth effect: Panel quantile regression evidence for the US, Finance Research Letters, 23, 19-22

Barth, M. and Ramey, V. (2002) The Cost Channel of Monetary Transmission in B. Bernanke and K. Rogoff (eds) NBER Macroeconomics Annual 2001, Volume 16, 199-256

Benkwitz, A., Lütkepohl, H. and Wolters, J. (2001) Comparison of Bootstrap Confidence Intervals for Impulse Responses of German Monetary Systems, Macroeconomic Dynamics, $5,81-100$

Bjornland, H. C. and D. H. Jacobsen (2013) House Prices and Stock Prices: Different Roles in the US Monetary Transmission Mechanism, Scandinavian Journal of Economics, 115(4), 1084-1106.

Boivin, J. and M.P. Giannoni (2006) Has Monetary Policy Become More Effective, Review of Economics and Statistics, 88(3): 445-462

Boivin, J. and M.P. Giannoni (2010) Global Forces and Monetary Policy Effectiveness in J. Gali and M.J. Gertler (eds) International Dimensions of Monetary Policy, Chicago IL: University of Chicago Press, pp: 429-478

Calza, A., T. Monacelli and L. Stracca (2013), Housing Finance and Monetary Policy, Journal of the European Economic Association, 11 (S1), 101-122.

Carstensen, K., O. Hulsewig and T. Wollmershauser (2009), Monetary Policy Transmission and House Prices: European Cross-Country Evidence, CESifo Working Paper 2750.

Catte, P., N. Girouard, R. Price and C. Andre (2004), Housing Markets, Wealth and the Business Cycle, OECD Working Paper No. 394. 
Christiano, L. J., M. Eichenbaum and C. Evans (1999), Monetary Policy Shocks: What Have We Learned and to What End?, in: J. B. Taylor \& M. Woodford (eds), Handbook of Macroeconomics, Vol. 1, Chapter 2, 65-148, Amsterdam: Elsevier.

Christiano, L. J., M. Eichenbaum and C. Evans (2005), Nominal Rigidities and the Dynamic Effects of a Shock to Monetary Policy, Journal of Political Economy, 113 (1), 1-45.

Clarida, R., J. Gali and M. Gertler (2000), Monetary Policy Rules and Macroeconomic Stability: Evidence and Some Theory, Quarterly Journal of Economics, 115(1), 147-180.

Del Negro, M. and C. Otrok (2007), 99 Luftballons: Monetary policy and the house price boom across U.S. states, Journal of Monetary Economics, Vol. 54(7), 1962-1985.

Favero, C. A. (2001), Applied Macroeconometrics, Oxford: Oxford University Press.

Frank, M. (2009), Inequality and growth in the united states: evidence from a new state-level panel of income inequality measure, Economic Inquiry Vol. 47, 55-68.

Fratantoni, M. and S. Schuh (2003), Monetary Policy, Housing, and Heterogeneous Regional Markets, Journal of Money, Credit and Banking Vol. 35(4), 557-589.

Girouard, N., M. Kennedy, P. Noord and C. Andre (2006), Recent House Price Developments: The Role of Fundamentals, OECD Working Paper No. 475.

Goodhart, C. and B. Hofmann (2004), Deflation, Credit and Asset Prices, in R. Burdekin and P. Siklos (eds.), Deflation: Current and Historical Perspectives, Cambridge: Cambridge University Press, 166-188.

Goodhart, C. and B. Hofmann (2007), House Prices and the Macroeconomy: Implications for Banking and Price Stability, Oxford: Oxford University Press.

Goodhart, C. and B. Hofmann (2008), House prices, money, credit, and the macroeconomy, Oxford Review of Economic Policy, Vol. 24(1), 180-205.

Gupta, R. and A. Kabundi (2009), The Effect of Monetary Policy on House Price Inflation: A Factor Augmented Vector Autoregression (Favar) Approach, University of Pretoria, Department of Economics, Working Paper 200903.

Gupta, R., S. M. Miller and D. van Wyk (2010), Financial Market Liberalization, Monetary Policy, and Housing Price Dynamics, University of Connecticut, Department of Economics, Working Paper 2010-06.

Hall, P. (1992) The Bootstrap and Edgeworth Expansion, New York: Springer-Verlag Iacoviello, M. (2000), House Prices and the Macroeconomy in Europe: Results from a Structural VAR Analysis, European Central Bank, Working Paper 18.

Iacoviello, M. (2004), Consumption, House Prices and Collateral Constraints: A Structural Econometric Analysis, Journal of Housing Economics, Vol. 13(4), 304-320.

Iacoviello, M. and S. Neri (2010), Housing Market Spillovers: Evidence from an Estimated DSGE Model, American Economic Journal: Macroeconomics, Vol. 2(2), 125-64.

Jarocinski, M. and F. R. Smets (2008), House Prices and the Stance of Monetary Policy, Federal Reserve Bank of St. Louis Review, July/August 2008, Vol. 90(4), 339-365. 
CHRISTIDOU, KONSTANTINOU, ROUMANIAS Monetary Policy and Housing Market

Mian, A. and A. Sufi (2011), House Prices, Home Equity-Based Borrowing, and the US Household Leverage Crisis, American Economic Review, Vol. 101(5): 2132-56.

Mishkin, F. S. (2007), Housing and the Monetary Transmission Mechanism, Federal Reserve Bank of Kansas City's 2007 Jackson Hole Symposium, Jackson Hole, Wyoming.

Musso, A., S. Neri and L. Stracca (2011), Housing, Consumption and Monetary Policy: How Different are the US and the Euro Area?, Journal of Banking and Finance, 35 (11), 30193041

Pesaran, M. H., and R. Smith (1995) Estimating Long-Run Relationships from Dynamic Heterogeneous Panels, Journal of Econometrics, 68(1), 79-113.

Sá, F., P. Towbin and T. Wieladek (2014), Capital Inflows, Financial Structure, and Housing Booms, Journal of the European Economic Association, 12(2): 522-546.

Vargas-Silva, C. (2008), Monetary policy and the U.S. housing market: A VAR analysis imposing sign restrictions, Journal of Macroeconomics, Vol. 30(3), 977-990. 


\section{Appendix}

Table A.1. Descriptive Statistics

\begin{tabular}{|c|c|c|c|c|c|}
\hline Variable & Mean & Minimum & Maximum & $\begin{array}{l}\text { Std. } \\
\text { Dev. }\end{array}$ & Observations \\
\hline \multicolumn{6}{|c|}{ Panel A: US-Wide and Regional Variables } \\
\hline$(\log )$ Real GDP & 16.0517 & 15.5959 & 16.4052 & 0.2320 & 103 \\
\hline$(\log )$ GDP Deflator & -0.2192 & -0.5622 & 0.0872 & 0.1791 & 103 \\
\hline (log) Housing Investment & 15.3186 & 14.7516 & 15.7154 & 0.2150 & 103 \\
\hline$(\log )$ Real House Prices & -0.3175 & -0.5468 & 0.0426 & 0.1785 & 103 \\
\hline Federal Funds Rate & 0.0537 & 0.0100 & 0.1139 & 0.0246 & 103 \\
\hline \multicolumn{6}{|l|}{ 30-years fixed mortgage rate } \\
\hline US-wide & 0.0847 & 0.0551 & 0.1449 & 0.0228 & 103 \\
\hline North Central Region & 0.0853 & 0.0559 & 0.1442 & 0.0227 & 103 \\
\hline North East Region & 0.0846 & 0.0558 & 0.1463 & 0.0229 & 103 \\
\hline South East Region & 0.0845 & 0.0548 & 0.1451 & 0.0229 & 103 \\
\hline South West Region & 0.0845 & 0.0547 & 0.1460 & 0.0228 & 103 \\
\hline West Region & 0.0848 & 0.0543 & 0.1441 & 0.0230 & 103 \\
\hline \multicolumn{6}{|c|}{ Panel B: State-Specific Variables } \\
\hline (log) Relative Real House Prices & 0.0330 & -0.6361 & 0.7300 & 0.1693 & 5150 \\
\hline$(\log )$ Real House Prices & -0.2845 & -1.1821 & 0.2061 & 0.2342 & 5150 \\
\hline (log) Relative Housing Investment & -7.0398 & -10.7515 & -4.0631 & 1.1793 & 5150 \\
\hline (log) Housing Investment & 8.2788 & 4.4659 & 11.4053 & 1.1944 & 5150 \\
\hline
\end{tabular}

Notes for Table A.1: Panel A reports descriptive statistics for US-wide variables, whereas panel B for state-specific variables. The 30-years fixed mortgage rates at the regional level are common for all states belonging to a particular region. These are defined as: (1) North Central Region: IA, IL, IN, MI, MN, ND, OH, SD, WI; (2) North East Region: AL, FL, GA, KY, MS, NC, SC, TN; (3) South East Region: IA, IL, IN, MI, MN, ND, OH, SD, WI; (4) South West Region: AR, CO, KS, LA, MO, NE, NM, OK, TX, WY; (5) West Region: AK, AZ, CA, HI, ID, MT, NV, OR, UT, WA. The time span is 1983:Q1 - 2008:Q3. 